\title{
ARTIGOS
}

Submetido 24.08.2015. Aprovado 09.11.2015

Avaliado pelo processo de double blind review. Editor Científico: Alexandre de Pádua Carrieri

DOI: http://dx.doi.org/10.1590/So034-759020160205

\section{ESTUDOS ORGANIZACIONAIS E FILOSOFIA: A CONTRIBUIÇÃO DE DELEUZE}

\author{
Organizational Studies and Philosophy: Deleuze's contribution \\ Estudios Organizacionales y Filosofía: La contribución de Deleuze
}

\begin{abstract}
RESUMO
O presente trabalho tem como objetivo examinar algumas das contribuições da Filosofia deleuzeana para os Estudos Organizacionais. Para tanto, primeiro farei uma leitura geral de sua obra, examinando três marcos de sua filosofia: seu conceito de diferença e suas implicações, a concepção de sujeito engendrada por ela e, finalmente, o papel e relevância de sua parceria com Guattari para concretização de seu projeto filosófico. Concluo que a Filosofia de Deleuze pode contribuir especialmente para estudos empíricos em organizações, fornecendo premissas básicas que podem orientar tais estudos. 0 artigo visa não só contribuir para uma melhor compreensão do complexo pensamento de um dos filósofos mais importantes do século XX no meio dos Estudos Organizacionais, mas também deseja preencher uma lacuna nesse campo que diz respeito à pungente necessidade de que a reflexão filosófica faça-se presente nele.
\end{abstract}

PALAVRAS-CHAVE | Deleuze, Filosofia, Ontologia, estudos críticos, pós-estruturalismo.

\begin{abstract}
This paper aims to examine some of the contributions of Deleuzian Philosophy to Organization Studies. To do so, first I will do a general reading of his work, examining three landmarks of his philosophy: his concept of difference and its implications; the conception of the subject engendered by it and, finally; the role and relevance of his partnership with Guattari for the realization of his philosophical project. I conclude that Deleuze's Philosophy can contribute especially for empirical studies in organizations by providing basic assumptions that could guide these studies. This article aims to contribute not only to a better understanding of the complex thought one of the most important philosophers of the twentieth century in the field of Organization Studies, but also wishes to fill a gap in this field concerning the poignant need for philosophical reflection do be made present in it.
\end{abstract}

KEYWORDS / Deleuze, Philosophy, Ontology, critical studies, poststructuralism.

\section{RESUMEN}

El presente trabajo tiene por objeto examinar algunas de las contribuciones de la Filosofía deleuziana a los Estudios Orgánicos. Para ello, primero se hará una lectura general de sus trabajos, examinando tres marcos de referencia de su filosofía: su concepto de la diferencia y sus implicaciones, el concepto de sujeto engendrado por ella y, por último, el papel y la relevancia de su colaboración con Guattari en la concreción de su proyecto filosófico. Se concluye que la Filosofía de Deleuze puede contribuir especialmente a estudios empíricos en las organizaciones, aportando supuestos básicos que pueden orientarlos. El trabajo no solo se propone contribuir a una mejor comprensión del complejo pensamiento de uno de los filósofos más importantes del siglo XX en el ámbito de los Estudios Orgánicos, sino también llenar un vacío en este campo, respecto a la lacerante necesidad de que se incorpore a él la reflexión filosófica.

PALABRAS CLAVE / Deleuze, Filosofía, Ontología, estudios críticos, postestructuralismo. 


\section{INTRODUÇÃO}

O objetivo do presente artigo é examinar a obra de Deleuze, um dos principais filósofos do século XX, em busca de algumas das contribuições do pensamento do autor para os estudos organizacionais. Frisa-se que Deleuze concebeu a filosofia como uma disciplina aberta e em aliança com os demais campos de conhecimento, o que converge com a necessidade pungente, e já expressada por influentes autores nos estudos organizacionais, de fazer com que a reflexão filosófica faça-se presente nesse campo (i.e Cooper, 1976, 2001, 2005; Jones \& Bos, 2007).

Gilles Deleuze (1925-1995) foi um filósofo cujo pensamento é ainda hoje cercado por antagonismos, visto como complexo e obscuro por uns e, por outros, tão tocante e acessível a ponto de ser possível multiplicar suas leituras e conceitos em meios aparentemente distantes da filosofia (como no meio da música, da literatura, do cinema etc.). À pressuposição de sua relevância, soma-se a afirmação, talvez enigmática, de Michel Foucault: viu-se produzir no saber ocidental "uma fulguração que levará o nome de Deleuze. Um novo pensamento é possível, de novo o pensamento é possível... ele está aí, nos textos de Deleuze, saltitante, dançante, diante de nós ... Um dia, talvez, o século será deleuzeano" (Foucault, 1987, pp. 80-81). É possível afirmar que existe uma clara sintonia entre os pensamentos desses dois autores (Agamben, 2000). No entanto, enquanto a obra de Foucault vem sendo consideravelmente debatida nos estudos organizacionais desde a década de 1990, a obra filosófica de Deleuze vem sendo deixada em segundo plano (com algumas exceções de artigos publicados em inglês, por exemplo: Lawley, 2005; Linstead \& Thanem, 2007; Thanem, 2004). No entanto, esses trabalhos limitam-se a analisar conceitos específicos da obra de Deleuze de maneira isolada. Argumento que esse ponto é problemático, já que tende a turvar tanto a discussão sobre a importância da reflexão filosófica para os estudos organizacionais quanto a inteligibilidade do propósito geral da obra de Deleuze.

Explorar o propósito geral da obra de Deleuze, no entanto, está longe de ser uma tarefa simples, já que abrangeu uma impressionante variedade de temas. O filósofo francês desenvolveu diversas monografias sobre filósofos (como Lucrécio, Leibniz, Espinosa, Hume, Kant, Nietzsche, Bérgson, Foucault etc.) bem como escritos sobre a música, o cinema, a literatura, a psicanálise e o marxismo. Machado (2009) afirma que, apesar de tal heterogeneidade, existiria uma espantosa homogeneidade de procedimento que faz transparecer a base comum de seu pensamento e, assim, torna possível examinar seu projeto filosófico, bem como sua relevância para o pensamento contemporâneo.
Vale frisar, além disso, que a heterogeneidade característica do pensamento desenvolvido por Deleuze é sua demonstração de que a filosofia constitui-se não como um pensamento passivo, ou uma reflexão sobre o mundo e seus fenômenos - conforme a clássica figura do filósofo como aquele sujeito que apenas observa, recebe informações do mundo, e reflete - mas como um exercício prático e imbricado na realidade. Ou seja, a filosofia deve ser vista como um exercício, como um processo ativo de criação que não trata de objetos abstratos que supostamente escapariam dos demais domínios do saber. Ao contrário, ela encontrar-se-ia em estado de aliança ativa e interna, percorrendo de maneira transversal os mais diversos domínios do saber, possibilitando a criação de novas maneiras de conhecer, novos problemas, novos conceitos, nos mais variados meios (Machado, 2009).

Em outras palavras, mesmo que as ciências e a filosofia componham campos de saber distintos, conforme explicam Zizek e Daly (2006), elas não possuem existências independentes. 0 que diferencia esses campos é, antes, uma diferença de nível em suas perguntas. Por exemplo, enquanto, por um lado, um cientista estudando o fenômeno organizacional poderia formular a pergunta: "Como a cultura local afeta a cultura organizacional da empresa X?”, um filósofo, por outro lado, provavelmente indagaria: "Quais são os conceitos, os pressupostos, que permitiram formular essa questão? Ela poderia ser diferente?”. O que existe, portanto, é uma conexão fundamental entre filosofia e ciência: enquanto uma formula perguntas e hipóteses a respeito de fatos concretos, a outra questiona seus pressupostos, ou o que permite ao cientista dizer o que ele diz, assim abrindo vias para novas perguntas, novas hipóteses.

Não se pode negar que essa conexão não foi sempre translúcida ao longo da tortuosa e complexa história da filosofia ocidental, muitas vezes inacessível em meios não filosóficos. Assim, argumento que um ponto que reforça a relevância da filosofia de Deleuze para os estudos organizacionais é o fato de que explorar sua obra pode ser um exercício pedagógico para não filósofos, já que ela traz consigo a necessidade de realizar uma análise e construir um entendimento sobre a história e tradição da filosofia ocidental, desde seus primórdios até seus principais desdobramentos durante o século XX.

A fim de alcançar o objetivo proposto, primeiramente analisarei o conceito central que está presente em todo o pensamento do filósofo francês: seu conceito de diferença. Explicarei como esse conceito foi utilizado por Deleuze para, ao mesmo tempo, criticar a tradição filosófica e forjar uma ontologia própria que possui claras implicações para a construção do conhecimento. Tendo feito isso, examinarei a concepção de sujeito presente no pensamento de Deleuze, 
que costuma ser fonte de desentendimentos entre teóricos, inclusive nos estudos organizacionais. Após ter examinado seu projeto filosófico, veremos como Deleuze colocou-o em prática em sua notória parceria com Guattari. O que veremos será o movimento da filosofia de Deleuze, que vai desde um projeto com vocação empírica até sua realização. Concluirei, então, que as contribuições de Deleuze para os estudos organizacionais repousam sobre essa vocação empírica, podendo fornecer algumas premissas básicas para a realização de pesquisas em organizações.

\section{A DIFERENÇA E SUAS IMPLICAÇÕES ONTOLÓGICAS}

Como poderia a filosofia tornar-se um exercício crítico, imbricado no mundo, que permite criar novos conceitos e novas questões? Talvez esta tenha sido a pergunta fundamental que moveu a filosofia deleuzeana. E buscar uma resposta para ela não foi uma tarefa simples. A ambição de Deleuze de realizar o que alguns chamaram de uma filosofia da multiplicidade (Machado, 1990) levou-o ultimamente à necessidade de constituir uma nova imagem do pensamento que seria oposta às tradições filosóficas de cunho dogmático, ortodoxo, metafísico, moral e racional existentes em seu tempo. Deleuze propôs-se a construir um pensamento sem imagem, que seria pluralista, heterodoxo, ético, trágico, ontológico. Craia (2009) explica que essa empreitada tinha como objetivo superar a maneira de pensar historicamente organizada em torno das figuras centrais da essência e do fundamento, que seria o motor dessas tradições. Para alcançar esse objetivo, Deleuze elaborou seu conceito de diferença.

A crítica deleuzeana às mais diversas tradições filosóficas talvez tenha sido o traço mais peculiar de sua obra. Foucault (1987) explica que Deleuze desmoralizou essas tradições, exibindo o que esse outro autor francês chamou de ruína moral à qual teria chegado o pensamento ocidental dentro de seus liames. Segundo o autor, essa ruína teria sido provocada pelo humanismo que passou a dominar o pensamento filosófico desde Kant, que colocou no homem o fundamento do conhecimento. Ou seja, pode-se dizer que Deleuze fez parte de uma geração de estudiosos que, assim como os estruturalistas, partem de um antidogmatismo e um anti-humanismo fundamental para elaborar suas teorias (Alliez, 1996). Tal crítica é especialmente tributária ao filósofo alemão Nietzsche e à sua noção de imanência, que por sua vez também colocava em xeque a maneira como o pensamento ocidental tendia a organizar-se em torno de uma essência ou de um fundamento.
Nietzsche foi quem primeiro afirmou que o pensamento deveria acolher as singularidades da vida em vez de conjurá-las ou de subjugá-las por meio dessas figuras (Deleuze, 1988). Antes dele, rejeitar essa racionalidade dominante era estar fadado a cair num abismo indiferenciado e informe, já que "Fora deste Ser ou desta Forma, não tereis nada senão o caos" (Deleuze, 1988, p. 109). Esclareço que o Ser aqui mencionado é o sujeito soberano presente em algumas tradições filosóficas, como em Kant, ou Deus, em outras, como em Descartes. A Forma faz referência à suposta objetividade e verdade previamente dada e não questionada dos objetos oferecidos ao conhecimento.

Foucault (2005) explica que, ao desdobrar a problemática da afirmação das singularidades, a filosofia de Deleuze declara o fim da filosofia como ela vinha sendo praticada ao longo dos séculos. Para ele, recusar a expiação da diferença é rejeitar, a um só golpe, metafísicos e dialéticos, é rejeitar a filosofia da evidência e da consciência. Aqui é importante ressaltar a distinção entre a crítica proposta por Deleuze e a dialética. Deleuze (2006b) explica que, enquanto sua filosofia trataria das singularidades da vida de uma maneira poética, invocando a criatividade e a mudança ao afirmar a diferença, a maneira da dialética de tratar tais singularidades seria a do político, que, antes de tudo, se preocuparia em negar e aprisionar o que difere para conservar ou prolongar uma ordem histórica que, por ser fortuita e passageira, exige instâncias de representação para manter-se de pé.

Em especial, Deleuze rejeitava sumariamente a dialética de Hegel, por acreditar que nela as singularidades são subjugadas por um pensamento ideal e moral. Dessa forma, Deleuze estende sua crítica não só ao idealismo de Hegel, mas a todos que de alguma maneira defendem a existência da verdadeira moral, da verdadeira fé, dos verdadeiros filósofos/críticos etc. Dessa forma, conclui-se que Deleuze propõe a exclusão de todo e qualquer fundamento previamente estabelecido, uma vez que estes ultimamente objetivam conduzir o saber a uma suposta verdade suprema. 0 pensamento da diferença impossibilita a existência de verdades supremas e abre o pensamento ao fortuito, à ação e à transformação (Colebrook, 2002). Assim, em nome da diferença, Deleuze propõe colocar uma crítica vitalista/ética no lugar de uma visão de mundo e uma crítica dialética/moral.

No entanto, é mister repetirmos a pergunta colocada por Agamben: 0 que pode ser um conhecimento que não tem mais como correlato a abertura ao mundo e a verdade, mas só a vida e seu errar? (Agamben, 2000, p. 170). Novamente Deleuze viu-se obrigado a questionar todo o meandro da história da filosofia, já que Aristóteles foi o primeiro a afirmar que não é possível haver ciência do acidente, que um saber precisa ser generalizável a fim de prover previsibilidade (ver Owen, 1978). Deleuze precisava 
formular outro vocabulário que permitisse distinguir a diferença do indiferente. Para isso, ele precisou flexionar esse conceito com outro conceito: seu conceito de repetição. Pode-se dizer sucintamente que a repetição seria o sensível da diferença, o fator que a torna inteligível, o fator que distancia a diferença da noção simplista do caos indiferenciado.

É válido esclarecer que Deleuze (2006b) utiliza o conceito de repetição para operar uma crítica à generalidade e à maneira como esta subsidia o que o autor chamou das duas grandes ordens de generalidade presentes na tradição do pensamento ocidental: uma ordem qualitativa das semelhanças e uma ordem quantitativa das equivalências. 0 autor explica que a generalidade pressupõe o fato de que um objeto de análise qualquer pode ser trocado ou substituído por outro sem perdas relevantes para aquele que analisa (Deleuze, 2006b). Deleuze (2006b) defende a existência de uma concepção de repetição que foge da ordem das generalidades: a repetição diria respeito ao que não pode ser substituído, ou seja, ao singular. Contrário à lógica da repetição vista como generalidade, Deleuze argumenta que, se a repetição acontece de fato na prática, sejam repetições da ordem das semelhanças ou das equivalências, esse fenômeno seria mais da ordem do milagre do que da lei, e que o fato de as repetições acontecerem exprimiria "uma singularidade contra o geral, uma universalidade contra o particular, um notável contra o ordinário, uma instantaneidade contra a variação, uma eternidade contra a permanência” (Deleuze, 2006b, p. 21).

Diante do exposto, pode-se dizer que Deleuze contesta o pressuposto de que no desenvolvimento de uma pesquisa o pesquisador possa colocar dois termos, casos ou indivíduos, como equivalentes uns aos outros. Isso ocorreria, por exemplo, em pesquisas quantitativas, quando organizações ou indivíduos são postos sob uma mesma classificação ou legenda, passíveis inclusive de serem representados graficamente. 0 conceito de repetição presente em Deleuze não aceita os termos de tais pesquisas, uma vez que argumenta que somente a diferença dá razão ao sensível ou aos fenômenos analisados, sendo a repetição apenas uma manifestação da diferença que não deixa de carregar seu cerne de singularidade. É seguindo essa visão que o filósofo francês propõe sempre extrair da repetição algo novo, extrair-lhe a diferença que a habita (Machado, 2009).

A intercambialidade entre os conceitos de diferençarepetição proposta por Deleuze é, em última instância, uma formulação ontológica, ou seja, devemos buscar no ser a chave para sua compreensão. A ontologia deleuzeana, no entanto, não pode ser reduzida a uma noção tradicional de ser (ou de eu). Ao contrário, é precisamente essa noção que Deleuze busca desconstruir. Em suma, sua estratégia para essa desconstrução poderia ser resumida da seguinte forma: a diferença desarticula os fundamentos objetivos da tradição filosófica, e a repetição por também ser diferença - dissolve seus fundamentos subjetivos, ou seja, o eu, e abre vias para experiências subjetivas singulares. Essa estratégia é inusitada na filosofia, já que os filósofos geralmente tomam como dado e como algo não problemático o que significa pensar, ser eu, a representação e a recognição de maneira geral (Deleuze, 2006a, p. 191). Deleuze clama, portanto, por outra concepção de sujeito: um homem de subsolo, que não se reconhece nos pressupostos subjetivos de um pensamento natural nem nos pressupostos objetivos de uma cultura de seu tempo e que não dispõe de compasso para traçar um círculo (Deleuze, 2006a, p. 191).

Deleuze decretou, assim, o fim do reinado da filosofia da representação, fundada em torno de pressupostos objetivos e subjetivos não questionados, e abriu caminho para a filosofia da diferença: onde se pode, de fato, pensar a diferença e a repetição, não no sentido abstrato da representação e suas ordens gerais, mas no sentido concreto e singular do jogo, experimentando-as, fazendo-as com as próprias mãos e palavras. Ou seja, o pensamento afasta-se da figura do filósofo "amigo do conceito", e de todos os pressupostos que lhe conferem tranquilidade, e reinsere o pensamento no horizonte do sensível. Ou seja, o pensamento é, para Deleuze, algo que não pode ser fundado, mas que deve ser sentido nas contingências dos encontros com aquilo que nos força a pensar, e que "pode ser apreendido sob tonalidades afetivas diversas, admiração, amor, ódio, dor” (Deleuze, 2006b, p. 203). Foucault (1987) finalmente esclarece que esse exercício do pensamento, liberto da representação e da recognição, é como um golpe de sorte, um acaso, uma ínfima diferença; a repetição como diferença descoberta e inerente ao ser.

\section{O SUJEITO EMPÍRICO DELEUZEANO}

Ao iniciar este tópico, é necessário esclarecer que o estatuto do sujeito é uma das principais fontes dos recorrentes malentendidos que cercam a obra de Deleuze. Neste tópico, argumento que seria um equívoco considerar que, ao descartar o sujeito kantiano, ou a autoconsciência hegeliana, Deleuze tenha apostado em um sujeito preso a estruturas e incapaz de agir. É importante frisar que esse mal-entendido reverbera de maneira ampla no campo dos estudos organizacionais, já que se estende a grande parte de seus estudos pós-estruturalistas/ pós-modernos. Argumento que o esclarecimento desse ponto depende do entendimento do que seria o empirismo de Deleuze, e como ele subverte a noção de experiência subjetiva (Colebrook, 2002). Deleuze buscou essa noção no filósofo escocês David Hume, cuja obra foi tema de seu primeiro livro, publicado ainda 
em sua juventude (Deleuze, 2001). Foi por meio da noção de empirismo encontrada em Hume que o filósofo francês buscou escapar de duas problemáticas ontológicas importantes: a objetivista (ou empirismo grosseiro) e a subjetivista (referente ao sujeito transcendente).

Scott (2010) argumenta que Deleuze interessou-se pela obra de Hume principalmente por vislumbrar nela uma alternativa ao sujeito transcendente kantiano. Segundo Deleuze (2009), Kant determinara que a subjetividade constitui-se a priori, ou seja, independentemente da experiência empírica. Para o autor, o "transcendental qualifica o princípio de submissão necessária dos dados da experiência às representações $a$ priori e, correlativamente, de uma aplicação necessária das representações a priori às experiências” (Deleuze, 2009, p. 22) Antes, para Deleuze, o sujeito constituir-se-ia a partir de um processo, não sendo um dado a priori: ele seria um sujeito prático que se constitui a partir de sua própria experiência. Contudo, é importante frisar que essa noção de sujeito não estaria presa ao dado (o que caracterizaria um empirismo vulgar, grosseiro, ou objetivista), ao contrário, o que seria peculiar em sua leitura de Hume é o fato de que, para ele, um sujeito só se constitui como tal a partir do momento em que ultrapassa sua própria experiência, ou seja, a partir do momento em que inventa e crê a partir do que the é dado na experiência. Nesse ponto residiria, portanto, o poder de ação do sujeito.

Segundo essa proposição, a subjetividade não seria nem teórica nem psicológica, ou seja, não constituiria um fundamento para o conhecimento nem poderia ser restrita a um domínio psicológico interno e próprio do sujeito: ela só poderia ser pensada como um movimento de subjetivação ou por um processo aberto de subjetivação. Deleuze e Guattari (2007) listaram de maneira bastante didática o que chamaram dos quatro grandes erros que, segundo os autores, afastaram - e ainda afastam a possibilidade de pensar segundo essa noção de sujeito: de início, a ilusão da transcendência; depois, a ilusão dos universais; depois, ainda, a ilusão do eterno; e, finalmente, a ilusão da discursividade. Assim, o último obstáculo encontrado para a maneira de pensar proposta por Deleuze foi o estruturalismo que veria apenas linguagem por toda parte. Contrariamente a essa visão, o objeto de interesse do pensamento, segundo Deleuze (1992), seriam os processos em constante estado de transformação: “... Esses processos operam em 'multiplicidades' concretas, sendo a multiplicidade o verdadeiro elemento onde algo se passa. São as multiplicidades que povoam o campo da imanência” (Deleuze, 1992, p. 182).

Deleuze apoia sua noção de sujeito no que se pode chamar de uma ontologia da multiplicidade, e, assim, ele foge também de uma ontologia realista, segundo a qual não haveria invenção ou crença, mas um estado de coisas previamente estabelecido que se impõe a um observador notadamente neutro. É importante frisar que, ao conceber tal noção de sujeito, Deleuze opera uma crítica sumária às seguintes tradições filosóficas: ao Eu unificador e individualizante de Kant; à fenomenologia, que, a seu ver, operaria uma redução fenomenológica ao transformar o mundo em um sistema de fenômenos, fato esse que abriria o campo da experiência como horizonte de uma subjetividade transcendental; como também à dialética, que somente captura o ser (a diferença) enquanto negação (Alliez, 1996).

A multiplicidade é o que escapa, portanto, de qualquer forma de representação (Schopke, 2004). A representação seria, pois, uma tendência a enxergar teorias como espelhos acurados da realidade em vez de abstrações representacionais arbitrárias, e, segundo apontou Chia (1995), tal tendência pode ser atribuída a uma longa tradição de comprometimento com uma ontologia realista tanto nos mais diversos campos do saber quanto na teorização e pesquisa organizacional. No entanto, a alternativa que nos é comumente apresentada à ontologia realista, ou seja, uma ontologia subjetivista, ainda estaria presa à noção de representação criticada por Deleuze, na medida em que esta se apoia em pressupostos como o do sujeito soberano. Portanto, se resgatamos as duas ontologias definidas por Burrell e Morgan (1979), vemos que, se o funcionalismo, por um lado, encaixa-se no objetivismo, a crítica tradicional ou modernista, por outro, estaria fundamentada por uma ontologia subjetivista, ambas as quais ainda presas a tais abstrações representacionais. Assim, corroboro a opinião de Deetz (1996) de que a visão dualista proposta por esses autores faz injustiça às agendas de pesquisas mais recentes nos estudos organizacionais, como a do pós-estruturalismo.

Contudo, definir uma ontologia deleuzeana deve ser feito com cautela, e algumas dificuldades ainda podem ser levantadas: se não estamos falando mais do sujeito nem do objeto, do que estamos falando? Como abordar essa realidade ao mesmo tempo não objetiva e não subjetiva em sua totalidade? Como propor uma agenda de pesquisa arraigada nessa imagem do pensamento? Para responder a essas questões, é necessário voltar-se à linguagem como ferramenta primordial para o pesquisador e, principalmente, explorar o conceito de acontecimento de Deleuze e suas implicações para conceber uma possível ontologia deleuzeana aplicável a estudos e análises empíricas. É preciso cautela nesse retorno à linguagem, e alguns aspectos da obra de Deleuze ainda necessitam ser examinados para que compreendamos como o autor escapa de uma análise que se resume a uma instância linguística ou estruturalista.

Assim, para concluir este trabalho, julgo imprescindivel conduzir uma leitura das contribuições específicas dos trabalhos 
de Deleuze feitos em parceria com Guattari. Argumento que é justamente por meio dessa parceria que Deleuze finalmente deixa claro seu rompimento com a estrutura, ou com uma preocupação puramente linguística, criando conceitos e amarrações teóricas que rompem a sua relação com o estruturalismo, que até então poderia ser considerada, no mínimo, ambígua. Argumentaremos que foi por meio dessa parceria que a obra de Deleuze assumiu contornos claramente políticos e pragmáticos (sobre o conceito de pragmática, ver Grisham, 1991). No próximo tópico, buscarei analisar como o pensamento do acontecimento deleuzeano desdobrou-se na prática e adquiriu novos contornos a partir do encontro com Guattari.

\section{Deleuze e Guattari: Praticando a filosofia deleuzeana}

No ano em que se conheceram, Deleuze havia acabado de publicar seu livro Diferença e Repetição (Deleuze, 2006b) e, logo em seguida, Lógica do Sentido (Deleuze, 2007). Era um tempo particularmente difícil para a filosofia como disciplina, uma vez que, no final da década de 1960, esta vinha sofrendo duros questionamentos em um ambiente onde ideias estruturalistas e as advindas da psicanálise ganhavam cada vez mais força. Isso acontecia também em meio ao turbilhão de acontecimentos políticos relacionados ao notório maio de 68 . Guattari era, nessa época, um discípulo de Lacan e psicanalista militante, e Deleuze, por sua vez, já se mostrava fascinado com as ideias da psicanálise. Não é de se espantar, portanto, o entrosamento que existia entre os dois teóricos (Dosse, 2011).

Sobre a importância de sua parceria com Félix Guattari, o próprio Deleuze afirma que, antes de começar a escrever com o psicanalista, ele se limitava a descrever um certo tipo de pensamento, mas que ainda estava distante de, de fato, fazê-lo ou exercitá-lo (Deleuze \& Parnet, 1980). Pode-se afirmar, dessa forma, que foi a partir de seu encontro com Guattari que Deleuze concluiu que não bastava formular um pensamento filosófico que dizia "viva o múltiplo"; era preciso fazê-lo (Droit, 1996). O Anti-Édipo e Mil Platôs, Capitalismo e Esquizofrenia (Deleuze \& Guattari, 1995a, 1995b, 1995C, 1995d, 2010) possuem, justamente, essa importância em sua obra.

Lecercle (2002) corrobora a tese de que a influência de Guattari fora decisiva também para demarcar um claro afastamento por parte de Deleuze do estruturalismo. Teria sido a partir da influência de Guattari que Deleuze desprende-se por completo da ideia estrutura e passa, então, a falar de máquinas e sistemas semióticos. No entanto, também é interessante frisar que Guattari teria se baseado em alguns elementos que encontrara na filosofia de Deleuze para formular uma concepção de máquina. A concepção de máquina elaborada pelo psicanalista não poderia ser reduzida à noção de estrutura, e dependeria da repetição do singular para concretizar-se. Ou seja, Guattari incorporou a seu aparato conceitual elementos da filosofia de Deleuze mesmo antes de iniciar seu trabalho em conjunto.

Deleuze, por sua vez, ainda apresentava uma atitude que poderia ser considerada ambivalente em relação ao estruturalismo. Sua leitura de como se podem reconhecer os estruturalismos na teoria, por exemplo, demonstrara certa fascinação com o método estruturalista, que, para Deleuze, tornara possível fazer circular seus elementos de análise em volta de um grau zero, uma casa vazia que tornaria o movimento das peças da estrutura possível (ver Deleuze, 2007). Segundo Dosse (2011), tal leitura pressupõe o fato de que Deleuze ainda via na estrutura um grau de equivalência com a máquina, o que fez com que o filósofo, tendo lido o ensaio Máquina e Estrutura de Guattari, ficasse tão impressionado a ponto de afirmar que Guattari estaria adiantado em relação a ele próprio em sua crítica ao estruturalismo (Dosse, 2011).

Guattari (1988) explica, em um de seus argumentos que impressionaram Deleuze, o fato de que a linguagem, antes de ser língua, seria uma política, e, por não existir língua em si, o fenômeno da existência de uma língua vista como uma unidade (como a língua portuguesa, por exemplo) seria somente possível a partir de uma formação de poder. Ou seja, a linguagem jamais poderia ser analisada, conforme queriam alguns estruturalistas de então, de maneira separada ou independente das relações de poder ou da política que precederia e garantiria a manutenção qualquer tipo de formação linguística unitária (Guattari, 1988, p. 24).

Além disso, Guattari (1995) afirma que o pensamento do maquinismo seria uma maneira possível de quebrar "a cortina de ferro ontológica” existente entre ser e coisas. A máquina teria tal papel e foi reconceitualizada pelo psicanalista francês como um meio-termo que atuaria como uma espécie de gênese entre inércia e movimento, ou seja, um estado de nada, de inércia, e um estado de sujeito não humano. 0 autor explica esse estatuto de sujeito não humano da máquina, afirmando que mesmo o objeto técnico não pode ser limitado à sua materialidade. A respeito desse ponto, Guattari (1995, p. 8) explica que, em qualquer tecnologia, existem elementos ontogênicos que escapariam do reino da materialidade, como: relações sociais que sustentam as próprias tecnologias, bolsões de conhecimento, relações de poder etc. Ou seja, existiria uma série de interfaces com as quais o elemento técnico entra em conjunção para existir. A máquina, antes de ser tecnológica, seria uma máquina social, ela constituiria uma relação de vizinhança entre termos heterogêneos e independentes (ver Deleuze \& Parnet, 1980). 
Também é importante frisar que o conceito de máquina presente em $O$ Anti-Édipo é sutilmente diferente da formulação anterior de Guattari. Em seu primeiro capítulo, intitulado Máquinas, Deleuze e Guattari (2010) afirmam que haveria somente máquinas por todas as partes. Os autores trataram de maneira específica do que chamaram de máquina social e máquina desejante. Enquanto a máquina social, por um lado, seria uma máquina instalada no nível semiótico de uma organização social, por outro lado, para que tal máquina codificadora/organizadora do socius possa funcionar, ela precisaria estar conectada a uma máquina que supõe produzir o fluxo a ser organizado: As máquinas desejantes estão à porta e quando entram fazem tudo vibrar; e o que não entra talvez faça vibrar ainda mais (Deleuze \& Guattari, 2010, p. 169). Vê-se que os autores parecem abrir mão, definitivamente, da dicotomia estrutura $x$ máquina como base de seu pensamento (mesmo que se tratasse de uma dicotomia antagônica - isto é, máquina contra a estrutura). Definir esses dois tipos de máquinas foi um primeiro passo no sentido de começar a trabalhar a ideia de agenciamentos e a ideia de máquina abstrata, desenvolvidas posteriormente pelos autores em Mil Platôs. A palavra agenciamento vem do francês agencement, que poderia também ser traduzida para o português como arranjo ou organização. Esse conceito teria duas facetas, um sentido de agência e a heterogeneidade dos elementos que o constituem.

Explicando melhor esse conceito, Deleuze e Guattari (1995b) colocam que os agenciamentos comportariam uma esfera de conteúdo e outra de expressão: de um lado, eles seriam agenciamentos maquínicos de desejo e, de outro lado, agenciamentos coletivos de enunciação. Os autores afirmam que os agenciamentos seriam distintos dos estratos ou das estruturas visíveis, porém se atualizariam neles (Deleuze \& Guattari, 1995d). A distinção dos dois lados de um agenciamento dá-se ao passo que, tanto nos estratos quanto nos agenciamentos, podemos distinguir conteúdo e expressão, ou o que se faz e o que se diz em determinada formação (como em uma formação histórica, por exemplo). Os agenciamentos não se reduziriam ao estrato no qual se atualizam, uma vez que, sob a ótica do agenciamento, a expressão torna-se um regime semiótico e o conteúdo um sistema pragmático. Isso se dá já que o agenciamento seria dinâmico e suporia movimento e transformações; muito distinto, portanto, da noção de uma estrutura estável.

Zourabichvili (2004) explica, a respeito de tal ponto, que se pode dizer estar na presença de um agenciamento quando é possível identificar um acoplamento entre os elementos de "um conjunto de relações materiais e de um regime de signos correspondentes" (Zourabichvili, 2004, p. 21). Aqui podemos concluir que existe no nível do agenciamento uma articulação onde a expressão age sobre o conteúdo, constituindo uma zona autônoma onde transformações incorporais exprimidas pela primeira inscrevem-se e incorporam-se ao segundo, compondo, assim, um regime semiótico que age sobre um sistema pragmático. Ao posicionar suas análises em um intermédio indiscernível de conteúdo e expressão, onde ambos são passíveis de serem transformados, os autores fazem um claro posicionamento político que nos leva, diretamente, ao conceito de rizoma formulado também por Deleuze e Guattari.

Conforme vimos anteriormente, Deleuze já havia preparado o terreno em sua filosofia para uma outra imagem do pensamento, e pode-se concluir que tal proposta tomou a forma do rizoma em suas formulações em conjunto com Guattari. Os autores sugerem como modo de pensar a forma rizoma, em oposição à forma árvore como modo de pensar tradicional. Um rizoma poderia ser visto como uma forma sem centro, sem hierarquia ou bordas. Por meio de tal modo de pensar, os autores pretenderam abrir a possibilidade de se conhecerem os arranjos heterogêneos de conteúdo e expressão pelo meio, sem um ponto de referência, uma imagem, ou uma estrutura preconcebida que orientaria o conhecer. Assim, os autores abrem as portas para a investigação de elementos que ficavam marginalizados pelas formas de conhecer dominantes, ou que lhes escapavam de alguma maneira.

\section{A FILOSOFIA DE DELEUZE E OS ESTUDOS ORGANIZACIONAIS}

Ao percorrer a obra de Deleuze, vimos que ele concebia a filosofia como um exercício prático, imbricado na realidade e, portanto, empírico por excelência. Assim, argumento que, nos estudos organizacionais, a filosofia de Deleuze tem o potencial de contribuir especialmente para pesquisas empíricas que buscam pensar o dia a dia das organizações. Essa conclusão está na contracorrente do que vem sendo observado em relação à utilização de Deleuze nos estudos organizacionais, geralmente limitada a análises de conceitos isolados do autor ou a trabalhos de cunho teórico que buscam em sua obra elementos para discutir o que seria o fenômeno do pós-modernismo ou pós-estruturalismo nesse campo (Cooper \& Burrell, 2006; Souza, 2012). Apesar de tais discussões serem necessárias, creio que seria um movimento esperado extravasá-las e colocar em pauta o desdobramento da ontologia deleuzeana em pesquisas empíricas no âmbito organizacional. A possibilidade e a importância de se realizar essa conexão já foram apontadas por Linstead e Thanem (2007).

A leitura geral da obra de Deleuze até aqui realizada possibilitou concluir que seus conceitos centrais de diferença e repetição cumpriram o papel de criticar a tradição filosófica e constituir uma ontologia peculiar que é inseparável de uma epistemologia. Segundo essa conjunção, o conhecimento é tido 
como algo que só pode ser construído a partir de um sujeito empírico, que experimenta, pensa a multiplicidade, que vai além do que the é dado, ou seja, que inventa e crê a partir dos dados. Ao trazer essa ontologia para o âmbito das pesquisas empíricas em organizações, a primeira conclusão a que chegamos é que ela seria incompativel com pesquisas quantitativas (que já partem de uma visão objetiva de mundo, e que têm a generalidade como prerrogativa). No entanto, vê-se que seria possível utilizar o pensamento de Deleuze em pesquisas qualitativas nesse campo.

É sabido que as pesquisas qualitativas compõem uma pletora, nem sempre convergente, de posições ontológicas, epistemológicas e metodológicas (Ballinger, 2004; EasterbySmith, Golden-Biddle, \& Locke, 2008; Goertz \& Mahoney, 2012; Krefting, 1991; Kuper, Lingard, \& Levinson, 2008; Meyrick, 2006; Pratt, 2008). Dessa maneira, os interessados em realizar um estudo qualitativo devem primeiramente declarar essas posições. Não deixar essas posições explícitas torna impossível expor a coerência das escolhas metodológicas feitas por esses estudos (Amis \& Silk, 2007; Hammerseley, 1992). Assim, as premissas da filosofia deleuzeana podem fornecer essas posições e, assim, ser uma contribuição importante de sua filosofia para esses estudos.

Com base nos critérios para classificar diferentes abordagens de pesquisa proposto por Cunliffe (2011), concluímos, a partir da leitura realizada de sua obra, que Deleuze estabelece as seguintes premissas que podem ser adotadas por pesquisas qualitativas em organizações:

- Premissa ontológica fundamental: a realidade é constituída por um rizoma de relações horizontais, em constante estado de transformação, onde se podem distinguir conteúdo e expressão (um conjunto de relações materiais imbricado em um sistema semiótico correspondente);

- Premissa sobre a natureza humana: os humanos são sujeitos empíricos, imbricados na realidade, e que se constituem a partir da experiência, são criativos e transformadores;

- Proposição epistemológica básica: criar a partir do dado e transformar a realidade;

- Possíveis estratégias de pesquisa: etnografia; pesquisa ação participante.

No que diz respeito a onde tais pesquisas poderiam ser realizadas, tais premissas são convergentes com estudos de caso em uma única organização ou com o estudo de diferentes organizações que componham uma mesma rede.

Uma ressalva importante presente em nossa leitura diz respeito ao papel e lugar ocupado pela linguagem em estudos de campo que queiram utilizar as premissas encontradas na filosofia de Deleuze. Conforme vimos, apesar de a linguagem ocupar uma posição importante, ela não ocuparia um lugar necessariamente privilegiado de análise. Assim, estudos que se apoiam exclusivamente em análise de dados de entrevistas ou outras análises textuais e de discurso não seriam compatíveis com as premissas encontradas na obra de Deleuze.

A reflexividade é também outro elemento imprescindivel que encontra embasamento nas premissas da filosofia de Deleuze, uma vez que, segundo elas, o pesquisador não pode ser tido como um observador neutro da realidade pesquisada. Diversos autores já pontuaram a importância desse elemento para pesquisas qualitativas (Ballinger, 2004; Berger, 2015; Cunliffe, 2003; Rhodes, 2009), sendo este considerado inclusive um critério para avaliar o rigor desses estudos. A necessidade de expor a figura do pesquisador e sua maneira de afetar e de ser afetado pelo campo empírico é uma discussão necessária entre adeptos da pesquisa qualitativa nos estudos organizacionais e convergente com elemento ético e mesmo trágico trazido pela nova imagem de pensamento proposta por Deleuze.

O que essa nova imagem do pensamento impõe ao pesquisador seria, portanto, um não compromisso com a moral, ou com a verdade absoluta. Esse não é, no entanto, um passe livre para que pesquisas qualitativas caiam em relativismos absolutos. Resta aqui uma transição da preocupação em distinguir um conhecimento falso do verdadeiro para uma preocupação que se situa no nível da criação e desdobramento de um determinado problema que o pesquisador deseja investigar. Tal noção de problema já estava presente na leitura do pensamento de Bergson feita por Deleuze (1999) e é também atribuída à necessidade de pensar a diferença fora da esfera da negação. A partir dessa leitura, Deleuze (1999) afirma que a busca pela verdade estaria revestida por um preconceito social que consistiria em preocupar-se apenas em avaliar se a solução para um determinado problema seria falsa ou verdadeira.

Pode-se dizer que, segundo essa leitura, o trabalho do pesquisador deve iniciar-se na análise da adequação do problema que está sendo colocado, e não na busca por uma suposta solução verdadeira para ele. Para o pensamento deleuzeano, o preconceito aqui mencionado levaria o pesquisador a acreditar na existência de uma verdade ou uma solução para todo e qualquer problema. Tal postura aboliria, de antemão, a possibilidade de ele exercer o potencial criativo que é próprio ao processo da pesquisa empírica, ou seja, o da criação e desdobramento de problemas de pesquisa. Além disso, não se pode esquecer que, segundo tais premissas, um problema de pesquisa seria sempre local e específico e, assim, o papel do pesquisador na condução de uma pesquisa seria primeiramente o de definir qual o problema que está sendo colocado e se é adequado às contingências onde o pesquisador está imbricado. 
Concluo também que essa noção de problema colocada por Deleuze exalta a íntima relação entre ontologia, epistemologia e, consequentemente, metodologia de pesquisa (ponto também foi observado por Zizek, 2011). Essa relação seria, por sua vez, uma expressão da íntima relação entre filosofia e ciência, pois, enquanto a ciência se ocupa de buscar e propor soluções para problemas, a filosofia ocupar-se-ia em produzir ou tentar extrair problemas e prover uma orientação para o pesquisador tanto na criação de problemas quanto na busca por suas respostas.

Assim, tais premissas encontradas na filosofia de Deleuze devem ser utilizadas como princípios norteadores que permitem analisar tanto a coesão da escolha de seu frame teórico quanto de suas escolhas metodológicas. Não se pode esquecer também que, segundo essa filosofia, uma metodologia de pesquisa já seria em si uma política, já que os métodos delimitam e moldam as respostas para a pergunta colocada pelo pesquisador. Ter um método significa estabelecer de antemão como a pergunta será respondida, ou seja, o método seria o processo que, em uma investigação empírica, cria a realidade investigada que, antes da intervenção de seus crivos, permanecia aberta e indeterminada. Além disso, ressalto finalmente que, segundo essas premissas, o pesquisador não pode ser tomado como um sujeito previamente dado e constituído: ele estaria, ao contrário, sendo produzido concomitantemente e completamente imbricado em uma realidade que seria aberta, processual e que, portanto, o coloca como o fator ou o elemento que atualiza e que é capaz de transformar a própria realidade pesquisada.

\section{CONSIDERAÇÕES FINAIS}

Neste trabalho, concluí que as premissas encontradas na filosofia de Deleuze podem ser utilizadas como princípios norteadores em pesquisas empíricas em organizações. Destaco em especial que a adoção delas pode conferir a trabalhos de campo de cunho pósestruturalistas e/ou pós-modernos nos estudos organizacionais uma coerência que muitas vezes ainda lhes falta, sanando a crítica segundo a qual esses trabalhos são taxados como excessivamente relativistas. Esta seria uma contribuição importante, já que tais abordagens têm se multiplicado nesse campo desde a década de 1990. Entre essas abordagens, se podem destacar: diversas manifestações de abordagens processuais (como a Teoria Ator Rede); trabalhos que utilizam abordagem pós-colonial; ou trabalhos que utilizam uma abordagem feminista.

Futuramente, a utilização dessas premissas em estudos empíricos pode viabilizar a realização de debates sobre as implicações da filosofia de Deleuze para práticas organizativas e/ou gerenciais recorrentes em empresas e demais organizações, o que foge do escopo deste trabalho.
Finalmente, é importante frisar que a filosofia de Deleuze está também sujeita a críticas. Entre os seus críticos contemporâneos, temos alguns famosos hegelianos, como o filósofo Slavoj Zizek, algumas vezes citado neste trabalho. Seria interessante, portanto, analisar como a filosofia de Deleuze converge ou diverge tanto com adeptos do hegelianismo quanto com algumas das abordagens processuais nos estudos organizacionais, das quais temos como precursores Karl E. Weick e Robert Cooper, por exemplo. Mesmo que isso não invalide as contribuições da filosofia deleuzeana aqui examinadas, julgo que seja necessário levar em consideração pensamentos possivelmente divergentes para melhor compreender as suas possíveis limitações.

\section{NOTA DE AGRADECIMENTO}

A autora agradece ao Prof. Rafael Alcadipani da FGV/EAESP, pelo apoio constante e pelos comentários que contribuíram para o aprimoramento do artigo.

\section{REFERÊNCIAS}

Agamben, G. (2000). A imanência absoluta. In. E. Alliez (Org.). Gilles Deleuze: Uma vida filosófica (pp. 169-192). Rio de Janeiro, RJ: Editora 34.

Alliez, E. (1996). Deleuze, filosofia prática [Edição especial]. Cadernos de Subjetividade, 71-76.

Amis, J. M., \& Silk, M. L. (2007). The philosophy and politics of quality in qualitative organizational research. Organizational Research Methods, 11(3), 456-480. doi:10.1177/1094428107300341

Ballinger, C. (2004). Writing up rigour: Representing and evaluating good scholarship in qualitative research. British Journal of Occupational Therapy, 67(12), 540-546. doi:10.1177/030802260406701204

Berger, R. (2015). Now I see it, now I don't: Researcher's position and reflexivity in qualitative research. Qualitative Research, 15(2), 219234. doi:10.1177/1468794112468475

Burrell, G., \& Morgan, G. (1979). Sociological paradigms and organisational analysis: Elements of the sociology of corporate life. Londres, Reino Unido: Heinemann.

Chia, R. (1995). From modern to postmodern organizational analysis. Organization Studies, 16(4), 579-604. doi:10.1177/017084069501600406

Colebrook, C. (2002). Gilles Deleuze. Oxford, Reino Unido: Routledge.

Cooper, R. (1976). The open field. Human Relations, 29(11), 999-1017. doi: 10.1177/001872677602901101

Cooper, R. (2001). Untimely mediations: Questing thought. Ephemera, 1(4), 321-347.

Cooper, R. (2005). Relationality. Organization Studies, 26(11), 16891710. doi:10.1177/0170840605056398

Cooper, R., \& Burrell, G. (2006). Modernismo, pós-modernismo e análise organizacional: Uma introdução. RAE-Revista de Administração de Empresas, 46(1), 87-100.

Craia, E. C. P. (2009). O virtual: Destino da ontologia de Gilles Deleuze. Revista de Filosofia Aurora, 21(28), 107-123. 
Cunliffe, A. (2003). Reflexive inquiry in organizational research: Questions and possibilities. Human Relations, 56(8), 983-1003. doi:10.1177/00187267030568004

Cunliffe, A. (2011). Crafting qualitative research: Morgan and Smircich 30 years on. Organizational Research Methods, 14(4), 647-673. doi:10.1177/1094428110373658

Deetz, S. A. (1996). Describing differences in approaches to organization science: Rethinking Burrell and Morgan and their legacy. Organization Science, 7(2), 191-207. doi:10.1287/orsc.7.2.191

Deleuze, G. (1988). Foucault. São Paulo, SP: Editora Brasiliense.

Deleuze, G. (1992). Sobre a filosofia. In P. Pal-Pelbart (Trans.). Conversações (pp. 169-193). São Paulo, SP: Editora 34.

Deleuze, G. (1999). Bergsonismo. São Paulo, SP: Editora 34.

Deleuze, G. (2001). Empirismo e subjetividade. São Paulo, SP: Editora 34.

Deleuze, G. (2006a). Diferença e repetição. São Paulo, SP: Editora Graal.

Deleuze, G. (2006b). Sobre Nietzsche e a imagem do pensamento. In L. B. L. Orlandi (Org.) A ilha deserta (pp. 175-183). São Paulo, SP: Editora Iluminuras.

Deleuze, G. (2007). A lógica do sentido. São Paulo, SP: Editora Perspectiva.

Deleuze, G. (2009). A filosofia crítica de Kant. Lisboa, Portugal: Edições 70.

Deleuze, G., \& Guattari, F. (1995a). Mil platôs: Capitalismo e esquizofrenia (Vol. 1). Rio de Janeiro, RJ: Editora 34.

Deleuze, G., \& Guattari, F. (1995b). Mil platôs: Capitalismo e esquizofrenia (Vol. 2). Rio de Janeiro, RJ: Editora 34.

Deleuze, G., \& Guattari, F. (1995c). Mil platôs: Capitalismo e esquizofrenia (Vol. 3). Rio de Janeiro, RJ: Editora 34.

Deleuze, G., \& Guattari, F. (1995d). Mil platôs: Capitalismo e esquizofrenia (Vol. 4). Rio de Janeiro, RJ: Editora 34.

Deleuze, G., \& Guattari, F. (2007). O que é a filosofia? São Paulo, SP: Editora 34

Deleuze, G., \& Guattari, F. (2010). O anti-Édipo: Capitalismo e esquizofrenia. Rio de Janeiro, RJ: Editora 34.

Deleuze, G., \& Parnet, C. (1980). Diálogos. Valência, Espanha: Pre-Textos.

Dosse, F. (2011). Gilles Deleuze \& Félix Guattari: Intersecting lives. Columbia: Columbia University Press.

Droit, R. (1996). Deleuze, um pensador plural e singular [Edição especial]. Cadernos de Subjetividade, 64-68.

Easterby-Smith, M., Golden-Biddle, K., \& Locke, K. (2008). Working with pluralism determining quality in qualitative research. Organizational Research Methods, 11(3), 419-429. doi:10.1177/1094428108315858

Foucault, M. (1987). Theathrum philosoficum. In Abreu, A. D. (Ed.) Nietzsche, Freud \& Marx: Theatrum philosoficum ( $4^{\mathrm{a}}$ ed., pp. 45-81). São Paulo, SP: Editora Princípio.

Foucault, M. (2005). Ariadne enforcou-se. In M. B. Motta (Org.). Ditos e escritos II: Michel Foucault, arqueologia das ciências e história dos sistemas de pensamento (pp. 141-144). Rio de Janeiro, RJ: Editora Forense Universitária.

Goertz, G., \& Mahoney, J. (2012). A tale of two cultures: Qualitative and quantitative research in the social sciences. Princeton, EUA: Princeton University Press.

Grisham, T. (1991). Linguistics as an indiscipline: Deleuze and Guattari's pragmatics [Special Issue: Deleuze \& Guattari]. SubStance, 20(3), 3654. doi:10.2307/3685178
Guattari, F. (1988). O inconsciente maquínico: Ensaios de esquizoanálise. Campinas, SP: Editora Papirus.

Guattari, F. (1995). On machines. In A. Benjamin (Ed.). Complexity: Journal of Philosophy and the Visual Arts, 6, 8-12. Hammersley, M. (1992). What's wrong with ethnography? London, Reino Unido: Routledge.

Jones, C., \& Bos, R. T. (2007). Introduction. In C. Jones, \& R. T. Bos (Eds.). Philosophy and organization (pp. 1-17). Londres, Reino Unido: Routledge.

Krefting, L. (1991). Rigor in qualitative research: The assessment of trustworthiness. The American Journal of Occupational Therapy, 45(3), 214-222. doi:10.5014/ajot.45·3.214

Kuper, A., Lingard, L., \& Levinson, W. (2008). Critically appraising qualitative research. British Medical Journal, 337, 687-692. doi:10.1136/bmj.a1035

Lawley, S. (2005). Deleuze's rizhome and the study of the organization: Conceptual movement and an open future. Tamara: Journal of Critical Postmodern Organization Science, 3(3-4), 36-49.

Lecercle, J. (2002). Deleuze and language. Nova Iorque, USA: Palgrave MacMillan.

Linstead, S., \& Thanem, T. (2007). Multiplicity, virtuality and organization: The contribution of Gilles Deleuze. Organization Studies, 28(10), 1483-1501. doi:10.1177/0170840607075675

Machado, R. (1990). Deleuze e a filosofia. Rio de Janeiro, RJ: Editora Graal.

Machado, R. (2009). Deleuze, a arte e a filosofia. Rio de Janeiro, RJ: Jorge Zahar Editor.

Meyrick, J. (2006). What is good qualitative research? A first step towards a comprehensive approach to judging rigour/quality. Journal of Health Psychology, 11(5), 799-808. doi:10.1177/1359105306066643

Owen, G. E. (1978). Particular and general. Proceedings of the Aristotelian Society, 54(1), -233-260. doi:10.1093/aristotelian/54.1.233

Pratt, M. G. (2008). Fitting oval pegs into round holes: Tensions in evaluating and publishing qualitative research in top-tier North American journals. Organizational Research Methods, 11(3), 481-509. doi:10.1177/1094428107303349

Rhodes, C. (2009). After reflexivity: Ethics, freedom and the writing of organization studies. Organization Studies, 30(6), 653-672. doi:10.1177/0170840609104804

Schopke, R. (2004). Por uma filosofia da diferença: Gilles Deleuze, o pensador nômade. São Paulo, SP: Editora da Universidade de São Paulo.

Scott, T. (2010). Organization philosophy: Gehlen, Foucault, Deleuze. Londres, Reino Unido: Palgrave Macmillan.

Souza, E. M. (2012). Pós-modernidade nos estudos organizacionais: Equívocos, antagonismos e dilemas. Cadernos EBAPE.BR, 10(2), 270283. doi:10.1590/S1679-39512012000200003

Thanem, T. (2004). The body without organs: Nonorganizational desire in organizational life. Culture and Organization, 10(3), 203-217. doi:1 $0.1080 / 14759550412331297147$

Zizek, S. (2011). Órgãos sem corpos: Deleuze e consequências. Rio de Janeiro, RJ: Cia de Freud.

Zizek, S., \& Daly, G. (2006). Arriscar o impossível: Conversas com Zizek. São Paulo, SP: Martins.

Zourabichvili, F. (2004). O vocabulário de Deleuze. Rio de Janeiro, RJ: Relume Dumará. 